\title{
El-nino effect on reservoir volumetric (A case study of the Batujai Dam on the island of Lombok)
}

\author{
I Wayan Yasa ${ }^{1 *}$, M Bisri ${ }^{2}$, M Solichin ${ }^{2}$, Ussy Andawayanti ${ }^{2}$ \\ ${ }^{1}$ Civil Engineering Faculty, Mataram University, West Nusa Tenggara, Indonesia \\ ${ }^{2}$ Water Resources Engineering Department, Universitas Brawijaya, Malang, 65145, \\ Indonesia
}

yasaiwayan68@gmail.com

Received 16-07-2019; revised 31-07-2019; accepted 20-08-2019

\begin{abstract}
El-Nino has been occurred from 1952 to 2016 with the types of weak, medium, strong and very strong. The event of El-Nino has significant impact on all aspects of economy, social, industry and agriculture. There is a decrease in the quantity of water resources such as in the reservoir where the reservoir inflow becomes very small and the water outflow becomes high. At the event of very strong El-Nino is occurred some of the reservoirs will dry. The aim of the research is to investigate the deficit capacity of the reservoir in the event of El-Nino. The data analyzed in this article were the volume of the half-month reservoir, especially in the event of El-Nino events. The analysis of frequency deficit probability was using Weibull probability and Log Pearson Type III distribution. The results show significant decrease in reservoir water volume over a very long-time period. The reservoir volume never reached maximum water level and persists for almost one year. The deficit of reservoir volumes reached was $16,01 \times 10^{6} \mathrm{~m}^{3}$, $18.64 \times 10^{6} \mathrm{~m}^{3}$, and $21,07 \times 10^{3} \mathrm{~m}^{3}$ for weak, moderate, and very strong El-Nino, respectively.
\end{abstract}

Keywords: El-Nino, impact, reservoir, volumetric

\section{Introduction}

Climate is the average quantity of weather physical phenomena, which is the extreme variation of seasons that take place locally, regionally or globally. In a certain area the weather can change rapidly from day to day even from hour to hour. These changes may include, among other things, the occurrence of temperature changes, the phenomenon of the shift in the occurrence of precipitation, the phenomenon of changes in wind intensity and the accumulation of clouds. Climate change with all its causes has factually occurred at the local, regional and global. The Increasing of emissions and greenhouse gas (GHG) concentrations resulted in global warming, followed by rising sea levels due to the expansion and melting of ice in the polar regions [1]. The rising of sea levels will increase the energy stored in the atmosphere leading to climate change such as El-Nino and La-Nina [3, 4]. The phenomenon of El-Nino and La-Nina is very influential on weather conditions/climate in Indonesian region which has a geographical archipelago. The air/wind circulation between Asian and Australian continents and Pacific and Atlantic oceans is quite high which placed Indonesia under a highly vulnerable to the effects of climate change. This is indicated by the occurrence of various disaster events. 
As it is located in the eastern part of Indonesia West Nusa Tenggara Province is very vulnerable to the El-Nino phenomenon. With almost $80 \%$ area is covered by dry land problems of water resources provision become the main priority problem to be solved. In such efforts the government has made a breakthrough by building facilities and infrastructure of water resources supplier. Currently the government has built 9 reservoirs which is three of the reservoirs were built in Lombok and six reservoirs in Sumbawa. The most common problem identified in these six reservoirs is that they are reservoir suffers drought during El-Nino events. In the worst case at the peak of dry season, the capacity of some reservoirs below the dead storage. The inflow component includes river flows and rainfall, while the outflow component is including water for irrigation, fresh water and lost water from reservoir. The occurrence of climate change in the form of El-Nino affects the water volume of the reservoir, thus affecting the operation pattern of the reservoir. The deficit of water reservoir at the time of El-Nino is crucially important to anticipate the water supply condition, which may also be used indicate the occurrence of El-Nino. There are two main purpose of this research: Firstly, to identify the decrease of deficit volumetric based on the type of El-Nino. Secondly to provide information related to the return period of deficit reservoirs volumetric.

\section{Material and Method}

The study was conducted at Batujai Dam, West Nusa Tenggara Province

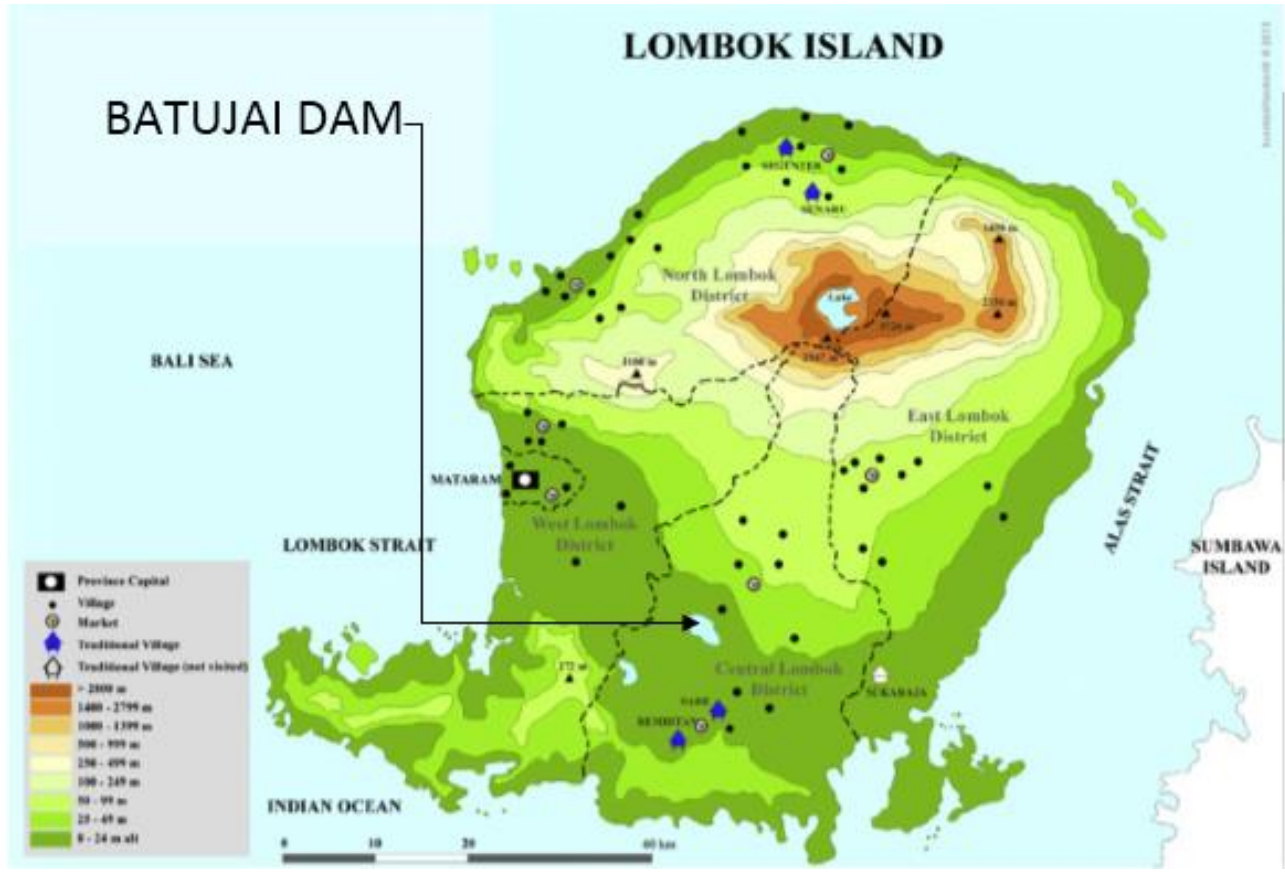

Figure 1. Map of reservoir Batujai location on Lombok island

Batujai Reservoir is built on Penujak River which flows from the slopes of Kundo and empties into the Lombok Strait with a river length of $54 \mathrm{~km}$ and a catchment area of $169 \mathrm{~km}^{2}$. Penujak river has characteristic of a large difference in river flow between dry and rainy seasons. In the rainy season the average monthly discharge can reach tens of cubic meters per second so it is a wastable potential to the sea, whereas in the dry season the average monthly debit can reach $0.1 \mathrm{~m}^{3} / \mathrm{s}$ or even less. The gross capacity reaches the value of $25 \times 10^{6} \mathrm{~m}^{3}$, effective $23 \times 10^{6} \mathrm{~m}^{3}$ and minimum capacity $1.4 \times 10^{6} \mathrm{~m}^{3}$. The phenomenon of global climate change is caused by the warming of the surface temperature of the eastern Pacific waters. El-Nino occurs in 2-7 years and lasts up to 12-15 months [7]. The characteristic of El- 
Nino is the periodic rise in temperatures in the Pacific region and the increased air pressure differences between Darwin and Tahiti [5].

One of the main challenges in dealing with climate change is how to link knowledge of impact with the adaptation actions [9]. In Indonesia, El-Nino events occur almost throughout the region and become a routine problem in the provision of water resources. Various anticipations have been made but often fail. The seasonal change event of El-Nino has a very strong effect on drought events. Furthermore, Chuthamat [3] reported that drought events can occur regionally and extensively covering several parts of the State.

Figure 2 shows climate change has occurred since 1950 until the year 2017 in the form of El-Nino and La-Nina events. El-Nino is a low-intensity rainfall below average and La-Nina is a high above average rainfall. El-Nino and La-Nina were reviewed based on anomalies of Sea Surface Temperature (SST Anomalies). Events are defined as 5 consecutive overlapping 3-month periods at above the $+0.5^{\circ}$ anomaly for warm events (El-Nino) and at or below the $-0.5^{\circ}$ anomaly for cold (La-Nina). There are several types of El-Nino and La-Nina which include weak (with a 0.5 to 0.9 SST anomaly), moderate (1.0 to 1.4$)$, strong (1.5 to 1.9$)$ and very strong $(\geq 2.0)[9]$.

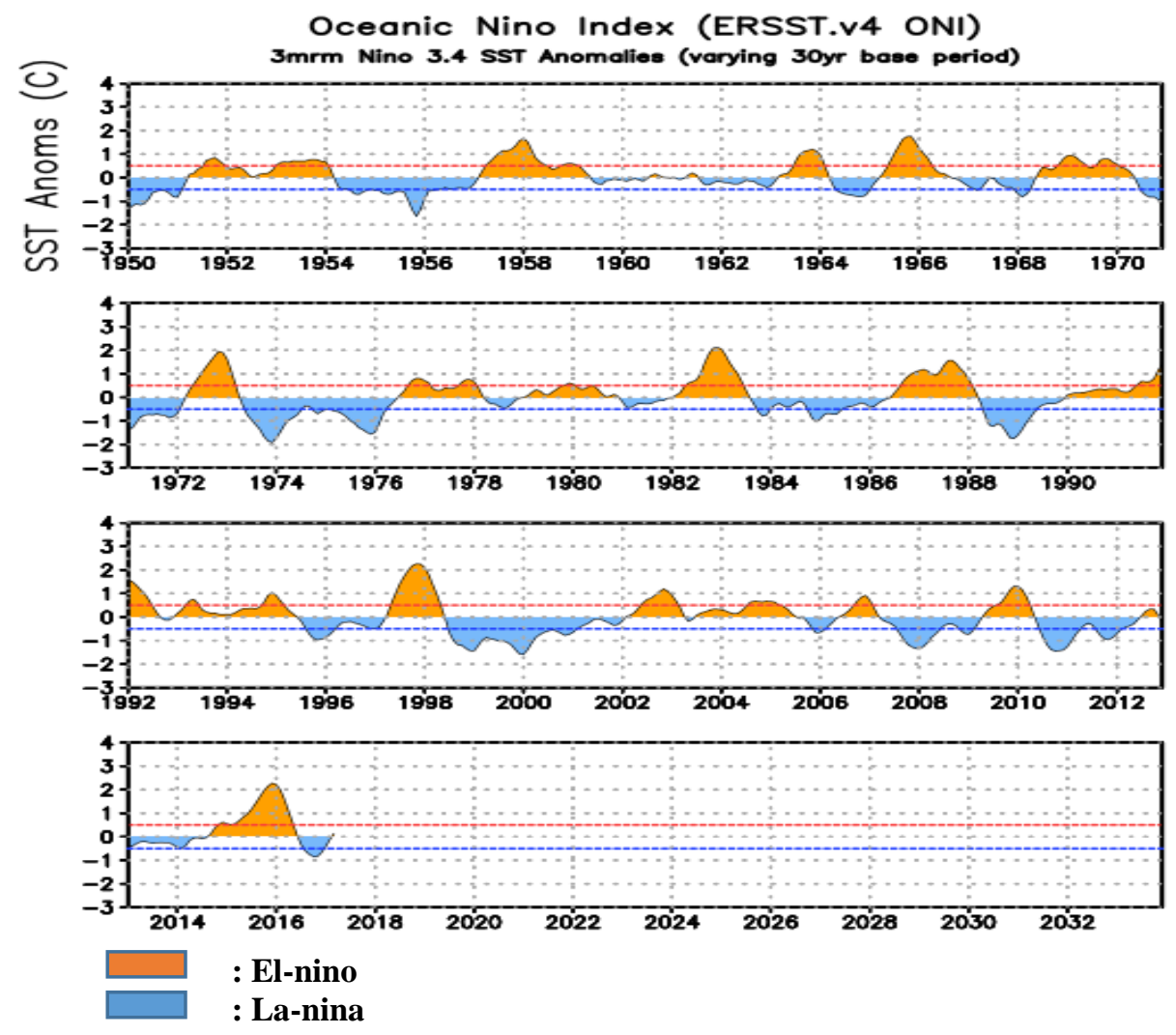

Figure 2. El-Nino and La-Nina Years

Recently, the potential impacts of climate change have been a major concern in the management of water resources. Climate change is indicated by the increasing of temperature of the earth's surface with a more extreme tendency [8]. Bhuvaneswari [2] reported that El-Nino has occurred since 1972, 1982, 1987, 1991, 1997, 2002 and 2004. El-Nino events are very influential on the hydrological process with the occurrence of a very significant flow reduction. Furthermore, Keener [5] stated that El-Nino has implications for the increasing uncertainty of water supply that affects the regulation of the allocation of water resources into complexes. One of the ways in which the construction of reservoirs is expected can be used as an anticipatory effort [7]. 
Reservoir is a very important facility in the water supply system and has many functions to hold water during the rainy season. The reservoir function is not only limited to the physical side such as capacity and flow but also depends on the needs and operating patterns. Further, Shiau [8] noted that reservoir is an important facility in multi-sector water supply system with the main function is to regulate the fluctuating surface water flow. Reservoirs have multipurpose uses, such as flood control, recreational activities, hydroelectric and water supply, which may conflict each other [9], water reservoir management must consider natural variability, especially climate change and land use change.

In the analysis of the possibility of occurrence of a hydrologic event in future, statistical analysis is an important tool that can be used. Statistical analysis has the advantage of using measurable hydrological data, therefore it is still considered to have good validity. Some common frequency distribution equation used in hydrology include normal distribution, normal logs, Gumbel, Pearson and Log Pearson Type III.

Mean:

$$
\begin{gathered}
\bar{X}=\frac{1}{n \sum_{i=1}^{i} X_{i}} \\
S=\frac{\sum_{i=1}^{i} X_{i}^{2}\left\{\left(\sum_{i=1}^{n} X_{i}\right) / n\right\}}{(n-1)}
\end{gathered}
$$

Coefficient of variation: $C_{v}=\frac{S}{\bar{X}}$

Skeweness

$$
: C_{s}=\frac{n}{(n-1)(n-2) S^{3}} \sum_{i=1}^{n}\left(X_{i}-\bar{X}\right)^{3}
$$

Kurtusis

$$
: C_{s}=\frac{n}{(n-1)(n-2)(n-3) S^{4}} \sum_{i=1}^{n}\left(X_{i}-\bar{X}\right)^{4}
$$

Furthermore, the magnitude of the reliable value of a hydrological even can be determined using the following can be equation.

$$
P=\frac{m}{n+1}
$$

Where:

$$
\begin{array}{ll}
\mathrm{P} & \text { : probability } \\
\mathrm{n} & \text { : amount of data. } \\
\mathrm{m} & \text { : serial number of data }
\end{array}
$$

The following equations are used to calculate the design deficit volumetric by the Log Pearson Type III method:

$$
\begin{aligned}
\log X & =\overline{\log X}+k \times S_{\log x} \\
\overline{\log X} & =\frac{1}{N} \sum_{i=1}^{n} \log X \\
S_{\log x} & =\sqrt{\frac{\sum_{i=1}^{n}(\log X-\overline{\log X})^{2}}{N-1}}
\end{aligned}
$$


Where:

$$
C s=\frac{N \sum_{i=1}^{n}(\log X-\overline{\log X})^{3}}{(N-1)(N-2)\left(S_{\log x}\right)^{3}}
$$

\begin{tabular}{ll}
$\log X$ & $:$ Logarithm of data \\
\hline $\log X$ & $:$ The mean logarithm of data \\
$\mathrm{S}_{\log \mathrm{x}}$ & $:$ Standard deviation from the data logarithm \\
$\mathrm{CS}$ & $:$ Coefficient of skewness \\
$\mathrm{k}$ & $:$ Frequency factor
\end{tabular}

\section{Results and Discussion}

The weak El Nino events occurred in 1994, 2004, 2005, 2006 and 2007. Although those events were classified as weak but they have significant impact on water volume reservoir. The decrease in water volume of the reservoir occurs simultaneously and never reached the effective capacity over a long-time period. The largest decrease in reservoir volume occurred in December at $16.01 \times 10^{6} \mathrm{~m}^{3}$. Decreasing the volume of the reservoir at the time of weak El-Nino does not lead to the provision of irrigation water is significantly reduced. The reservoir volume can still provide water because inflow from the river is still available. The weak El-Nino pattern almost shows the same trend from year to year. The reservoir volume is reduced more extreme for only 4 months but does not interfere with the operation of the reservoir.

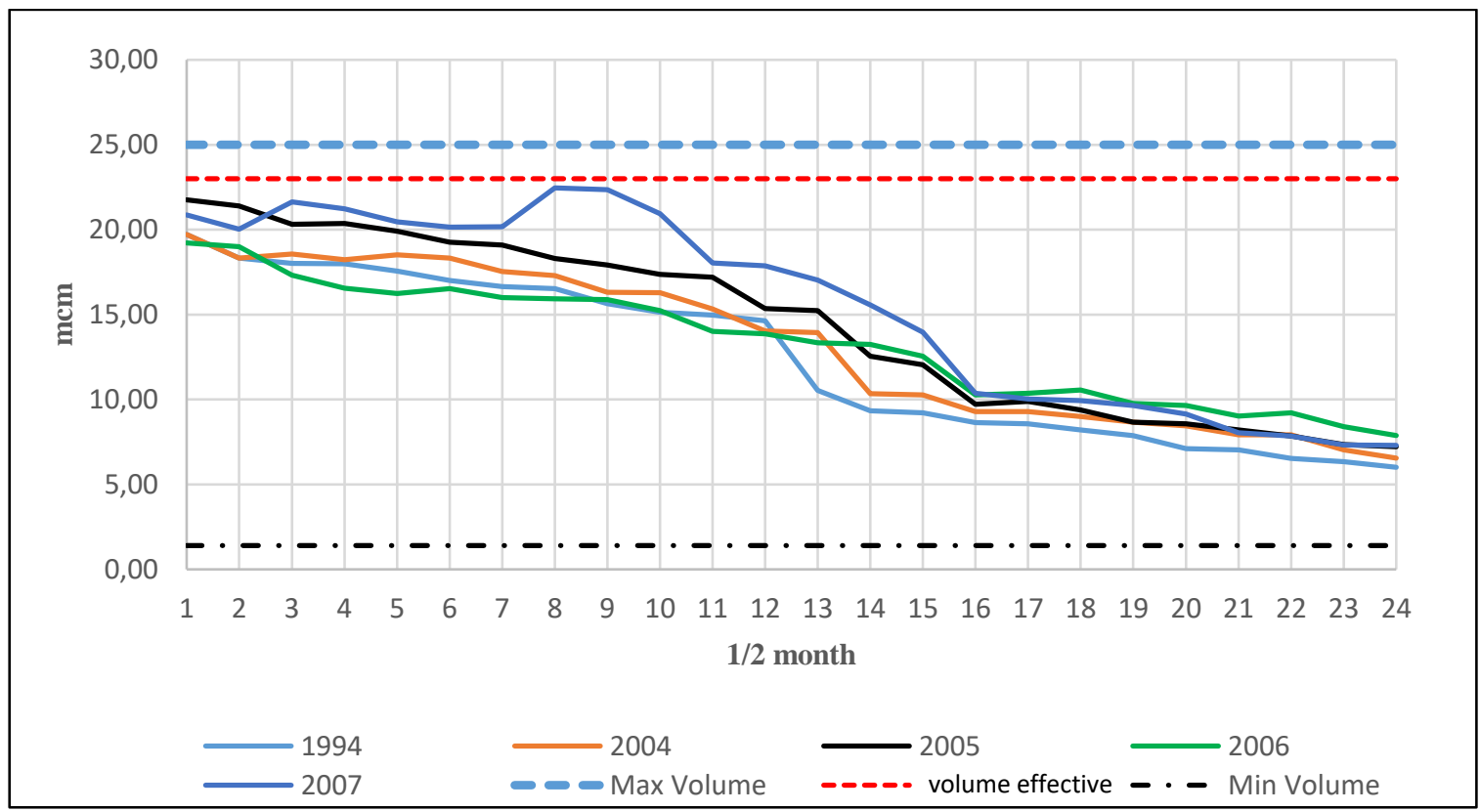

Figure 3. The volumetric deficit of the reservoir at the time of weak El-Nino

In the case of moderate El-Nino events the changes in reservoir volume are more extreme than the weak El-Nino. The extreme decrease in reservoir volume starts from April to December. In this event the volume of the reservoir is always below the effective but not under the minimum storage. The reservoir deficit volume from the effectiveness limit reaches $16.67 \times 10^{6} \mathrm{~m}^{3}$, thus almost every El-Nino event occurs. The decrease in reservoir volume occurs very extreme and has an impact on the fulfillment of irrigation water. The duration of the decrease in reservoir volume is quite long for almost 6 months. The pattern of occurrence of moderate El-Nino shows the same pattern both time and reduced reservoir volume. The moderate El-Nino event has occurred 5 times in 1991, 1992, 2002, 2003 and 2009. 


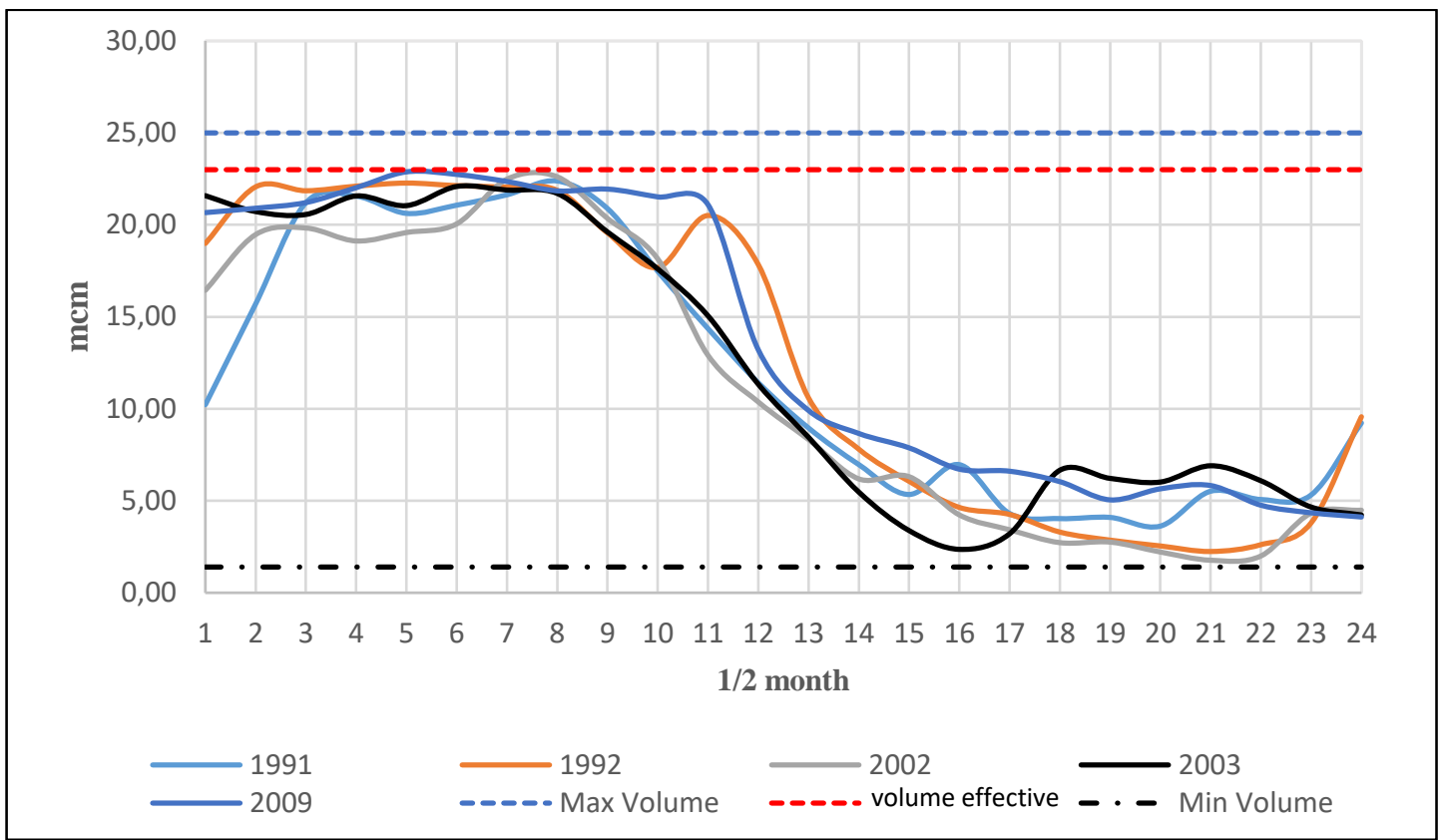

Figure 4. The volumetric deficit of the reservoir at the time of moderate El-Nino

The strong El-Nino event has occurred in the period 1982 - 1983, the period 1997- 1998 and 2015. The impact of El-Nino has caused a very extreme reservoir volume deficit. During the occurrence of ElNino the water volume of the reservoir is under the effective volume of the reservoir. In 1983 and 2015 the deficit of reservoirs reached the minimum reservoir or dead storage. The maximum deficit of the reservoir from the effective crater is $21.07 \times 10^{6} \mathrm{~m}^{3}$. The decreasing rate of the reservoir volume is quite high with a long period of 9 months. If the El-Nino occurs in the following years it will have an impact on the drought and affect the physical building of the reservoir.

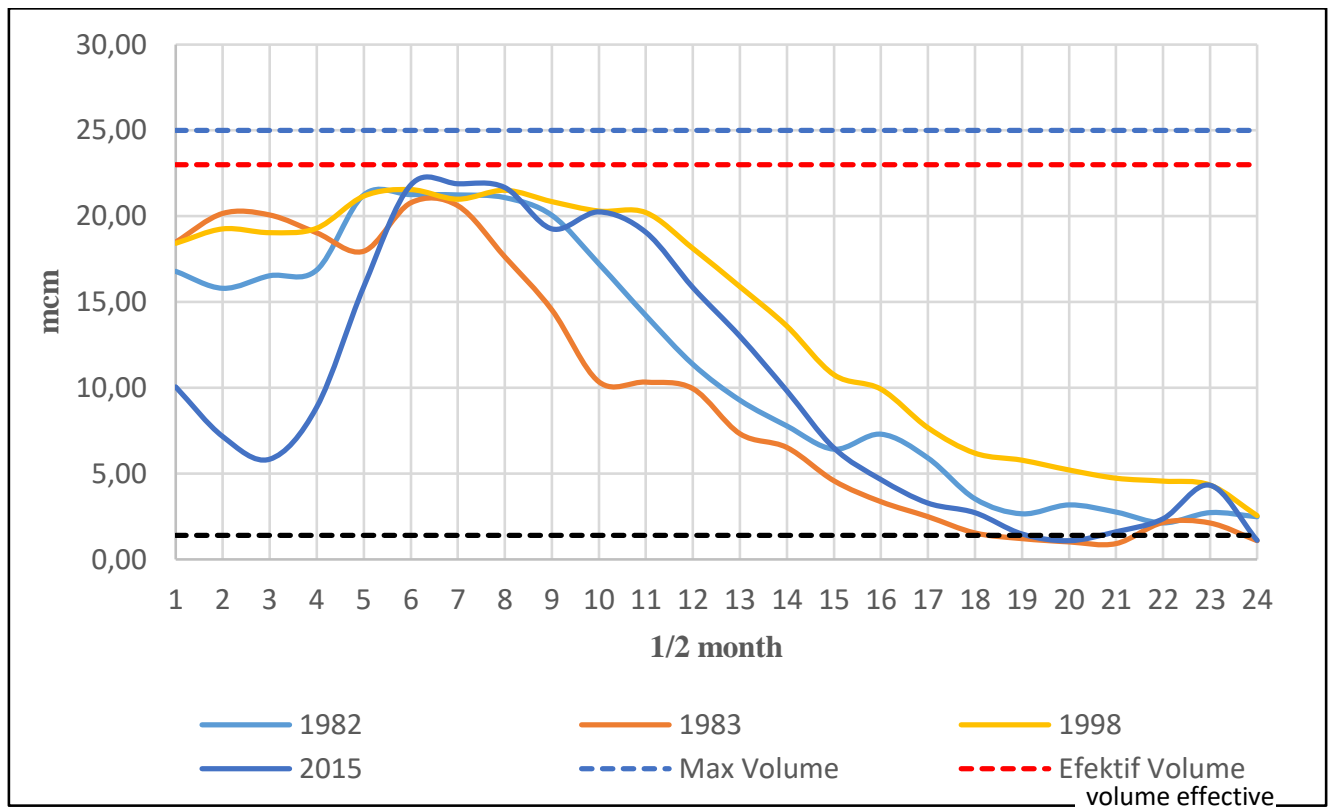

Figure 5. The volumetric deficit of the reservoir at the time of very strong El-Nino 
The return period indicates a magnitude of the occurrence likely to be equal of exceeds over that time span. Return period are often used in water planning to determine the magnitude of the design discharge. In this study, the return period deficit of reservoir defects was analyzed for each El-Nino type. Some return period deficit reservoir defects include 1, 2, 5, 10, 20 and 50 years. The volumetric deficit of the reservoir for each El-Nino event predicted using the Log Pearson Type III is shown in Figure 6. It was clearly shown that on the 5-year period the deficit reservoir is large enough for all El-Nino types. Reservoir deficit are strong El-Nino of $18.98 \times 10^{6} \mathrm{~m}^{3}$, moderate $11.24 \times 10^{6} \mathrm{~m}^{3}$ and weak $13.13 \times 10^{6} \mathrm{~m}^{3}$. While the extreme drought of the reservoir is going to be occurred at the time of the 10 periods.

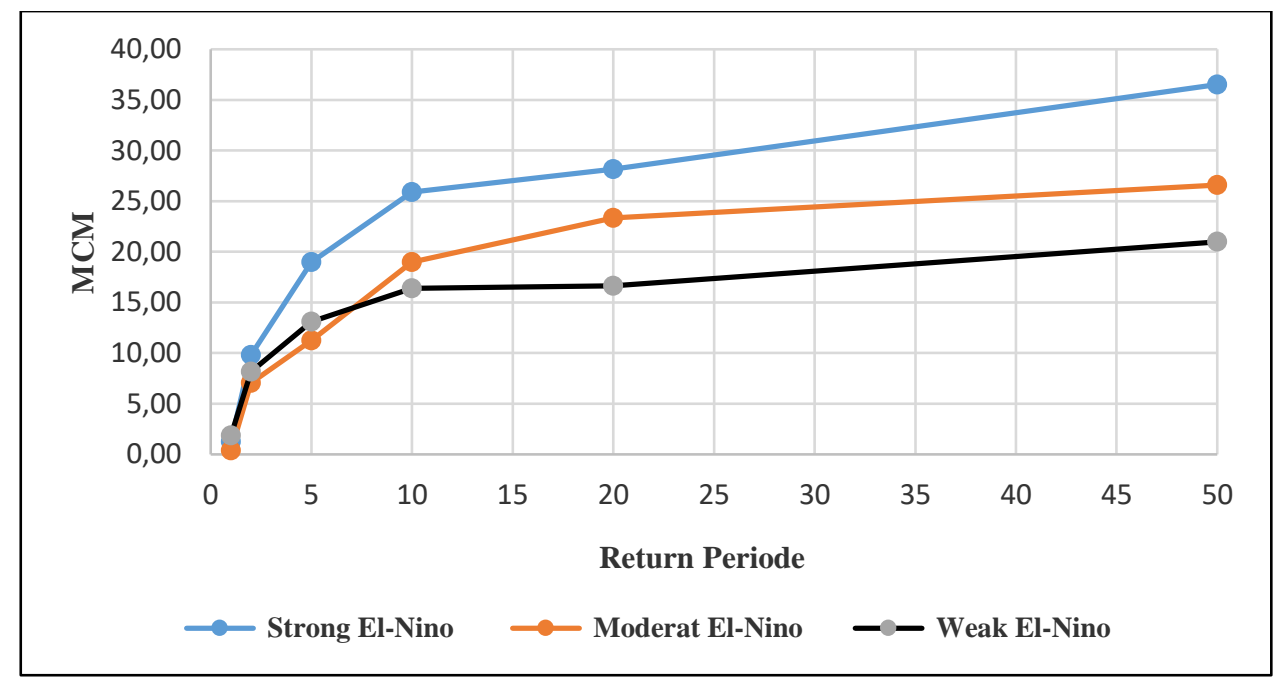

\section{Conclusions}

Figure 6. Return period deficit of reservoir volumetric

The El-Nino events may have a significant decrease in deficit reservoirs where reservoir volumetric never reaches an effective storage volume. During the El-Nino event, the strong deficit of the reservoir volume can reach under the volume of the dead storage. The maximum deficit volume of the reservoirs in each type El-Nino is $16.01 \times 10^{3} \mathrm{~m}^{3}, 18.99 \times 10^{3} \mathrm{~m}^{3}$ and $21.07 \times 10^{3} \mathrm{~m}^{3}$ for week, moderate and strong El-Nino respectively. The length of time for El-Nino events are different, where El-Nino moderate and El-Nino strong are longer than weak El-Nino. Probability occurring El-Nino events that cause reservoir volume to reach the minimum volume that is in the repeat period above 5 years

\section{Acknowledgments}

The authors wish to thank Department of Public Works West Nusa Tenggara Province for data throughout the study. We do appreciate to anonymous reviewers and editor for their valuable comments and suggestions.

\section{References}

[1] Ahidul I, Thian Y.G. 2015 Potential combined hydrologic impacts of climate change and El Niño Southern Oscillation to South Saskatchewan River Basin, Journal of Hydrology

[2] Bhubaneswar K., Geethalakshmi V. 2013 The Impact of El Niño/Southern Oscillation on Hydrology and Rice Productivity in the Cauvery Basin, India: Application of the Soil and Water Assessment Tool, Weather and Climate Extremes

[3] Chuthamat C., Adebayo J. Adeloye, and Soundharajan B.S. 2016 Inflow forecasting using Artificial Neural Networks for reservoir operation, IAHS, 373, 209-214

[4] Jie-Lun C, Yu-Shiue T. 2012 Reservoir Drought Prediction Using Support Vector Machines, Applied Mechanics and Materials Vol. 145 (2012) pp 455-459

[5] Keener V.W., Feyereisen G.W., Lall U., Jones J.W., Bosch D.D., R. Lowrance R. 2010 ElNiño/Southern Oscillation (ENSO) influences on monthly $\mathrm{NO}_{3}$ concentration, stream flow and 
precipitation in the Little River Watershed, Tifton, Georgia (GA) Journal of Hydrology, 381 (2010) 352-363

[6] Neil M.W., Casey M. B., Kye M. B., Yasir H. K. 2013 Reservoir performance and dynamic management under plausible assumptions of future climate over seasons to decades, Climatic Change (2013) 118:307-320

[7] Shu-Yi L., Chi-Chung C., Shih-Hsun H. 2010 Estimating the value of El Niño Southern Oscillation information in a regional water market with implications for water management, Journal of Hydrology

[8] Shiau J.T. 2003 Water Release Policy Effects on the Shortage Characteristics for the Shihmen Reservoir System during Droughts, Water Resources Management 17: 463-480, 2003

[9] Uriel F. H. A., Mélanie T., Robert L. 2014 Impacts and Adaptation to Climate Change Using a Reservoir Management Tool to a Northern Watershed: Application to Lièvre River Watershed, Quebec, Canada, Water Resour Manage, 28:3667-3680 